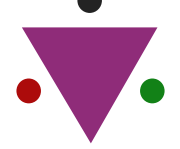

IJCRR

Section: Healthcare

Sci. Journal Impact

Factor: $6.1(2018)$

ICV: 90.90 (2018)

(c) (1) (3)

Copyright@IJCRR

\title{
To Study the Outcome/Analysis of Fracture Distal End Radius Managed with Antegrade K/L-Wire Fixation
}

\author{
Abhiram Awasthi' ${ }^{1}$, Kiran Saoji ${ }^{2}$, Prachi Palsodkar ${ }^{3}$ \\ Junior Resident, Department of Orthopaedics, Datta Meghe Institute of Medical Sciences, Jawaharlal Nehru Medical College, Sawangi \\ (Meghe), Wardha, Maharashtra, India; ${ }^{2}$ Professor and HOD, Department of Orthopaedics, Datta Meghe Institute of Medical Sciences,

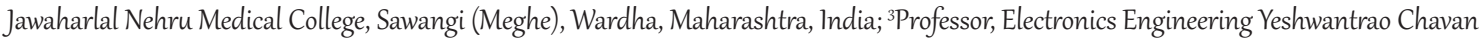 \\ College of Engineering, Nagpur, India.
}

\section{ABSTRACT}

Introduction: The treatment options for fracture lower end radius range from closed reduction and cast application to interlock nailing to the application of external fixators. Despite the advancements in treatment, close reduction and immobilization in the cast still prevail the standard reliable method for the management of minimally displaced intra-articular and extra-articular distal end radius fractures. The gold standard for the treatment of distal end radius fractures remains to be Volar Locking Plate Osteosynthesis. In this study focused on the alternative modality for the treatment of fracture distal end radius managed with antegrade k-wire fixation.

Mathods: This will be a prospective interventional study conducted on 30 patients between the age group of 18 to 60 years. In this modality, the distal end radius fracture is fixed with $2-3 \mathrm{k} / \mathrm{l}$ wires in the antegrade direction. Detailed clinical, radiological and functional assessment was done and after fulfilling the inclusion and exclusion criteria patients were selected. Data was spread on the master chart and analyzed

Expected Results: Results will be assessed after the study has been completed. Treatment with Intramedullary L-wire fixation is a cost-effective alternative which can also be performed in rural health setups. they are less invasive and overall provide better compliance for the patient. The results will be calculated with the help of SPSS software version 26.

Conclusion: Treatment with Intramedullary L-wire fixation is a cost-effective alternative which can also be performed in rural health setups. they are less invasive and overall provide better compliance for the patient.

Key Words: Fracture, Radius, K-Wire, Fixation

\section{INTRODUCTION}

Abraham Colle's first described distal end radius fractures and wrist fractures in the year 1814 about 200 years ago in terms of the carpal extremity of radial fractures but still, a percentage of unsatisfactory results in the management of lower end of radius fractures seems to be higher, with increased injury-related morbidities. ${ }^{1-3}$ As stated by Colles ${ }^{4}$ that wrist gains good functional freedom with or without intervention in all range of movements and can also be pain-free. The treatment methods for distal end radius fracture ranges from closed reduction and cast application to interlock nailing to external fixators. Despite the progress in managing distal end radius fractures, the primary closed reduction and casting immobilization is the profound standard non-surgical method for managing all extra-articular fractures which are stable and all minimally displaced intraarticular fractures. Such management modality for all intraarticular unstable fractures is liable for failure. Despite all such different management modality by various methods has shown promising results but volar locking plate osteosynthesis still holds the gold standard method in treating distal end radius fractures..$^{5-8}$

An alternative to volar plating that is antegrade intramedullary $\mathrm{k}$ wiring, has the advantage of decreasing the risk of tendon injury as well as screw penetration into the joint, that are the biggest issues related to volar plating. ${ }^{9,10}$ The procedure used for intramedullary $\mathrm{k}$ wire fixation also reduces the

\section{Corresponding Author:}

Dr. Abhiram Awasthi, Junior Resident, Department of Orthopaedics, Datta Meghe Institute of Medical Sciences, Jawaharlal Nehru Medical College, Sawangi (Meghe), Wardha, Maharashtra, India; Contact: 7000427564; Email: abhiram.awasthi2@gmail.com

ISSN: $2231-2196$ (Print)

Received: 23.09 .2020
ISSN: $0975-5241$ (Online)

Revised: 26.10 .2020
Accepted: 09.11 .2020
Published: 30.11 .2020 
risk of injury to pronator quadratus. antegrade $\mathrm{k}$ wire fixation also can improve wrist strength and function, distal radioulnar joint stability, and metalwork soft-tissue cover. The Kirschner-wire (K-wire) retrograde fastener is either extra focal-bicortical ${ }^{9,11}$ or intrafocal-unicortical. ${ }^{12}$

\section{MATERIALS AND METHODS}

Study design: An interventional prospective study

Setting: The study would be conducted on patients of fracture distal end radius being treated by operative methods in Orthopaedic Department at Acharya Vinoba Bhave Rural Hospital Sawangi Wardha under Jawaharlal Nehru Medical College Sawangi, Wardha during May 2019to April 2021.

Participants: Adults from the age group 8 to 60 years were included in the study belonging to any sex.

Study size: A sample size of the study will be 30 .

\section{Inclusion criteria}

- Adults from 18 years and above

- Fractures reporting within 3 weeks of injury

- Patients willing to participate in the study

- Dorsal angulations greater than 10 degrees or radial height shortening of more than or equal to $5 \mathrm{~mm}$

\section{Exclusion criteria}

- Compound fractures

- Fractures older than 3 weeks

- Fractures involving intraarticular surface of wrist joint

- Neurovascular involvement

- High-velocity trauma with multiple small pieces

- Patients not willing to participate in the study

\section{EXPECTED RESULTS}

The expected outcome of this study is to establish an alternative modality for the treatment of fracture distal end radius. The fracture is managed with antegrade $\mathrm{k} / \mathrm{L}$ wire fixation and is compared with standard management methods like plating and cast applications as it is a cost-effective and relatively easy procedure for fracture reduction and treatment.

\section{DISCUSSION}

Minimally displaced or undisplaced displaced fractures of distal end radius managed conservatively show good results but as of now for severely undisplaced and Intraarticular fractures the best possible treatment or the gold standard of treatment is controversial. External fixation, percutaneous pin insertion followed by cast application and plating are favourable in reducing wrist pain and arthritis and in prevent- ing malunion ${ }^{13}$. In the bone is not osteoporotic or fracture is not severely comminuted then relatively cheap techniques like percutaneous pinning in trans styloid manner or Kapandj technique can be used ${ }^{3}$. But as the pin insertion is in very close proximate to the wrist joint articulation can cause many complications related to the articular surface of wrist joint with possibility of other complications such as nerve injuries, skin irritations, tendon rupture can happen. ${ }^{14-17}$ To avoid these complications and to find an alternative way to treat distal end radius fractures antegrade k-wire fixation was done. The complication rates with percutaneous pinning and cast application were found to be $42 \%^{18}$, those with Kapandji procedure were $20 \%$ and trans styloid pinning was $10 \%{ }^{19}$ and trans styloid pin insertion accompanied by cast application were $33 \%{ }^{20}$ The soft tissue complication rates in our study are expected to be lower than these alternatives. Presence of systemic disorders like hypertension ${ }^{21}$, diabetes ${ }^{22}$ also plays a key role in fracture healing and treatment of these underlying entities needs to be addressed properly. Few of the other related studies on bone and joint disorders are available. ${ }^{23}$

\section{CONCLUSION}

Will be done on completion of the study and data analysis.

\section{REFERENCES}

1. Owen RA, Melton 3rd LJ, Johnson KA, Ilstrup DM, Riggs BL. Incidence of Colles' fracture in a North American community. Am J Public Health 1982 Jun;72(6):605-7.

2. Jupiter JB. Current concepts review: fractures of the distal end of the radius. J Bone Joint Surg Am 1991 Mar;73(3):461-9.

3. Simic PM, Weiland AJ. Fractures of the distal aspect of the radius: changes in treatment over the past two decades. JBJS 2003 Mar;85(3):552-64.

4. Colles A. On the fracture of the carpal extremity of the radius. Edinb Med Surg J. 1814;10:181. Clin Orthop Relat Res 2006 Apr;445:5-7.

5. Mostafa MF. Treatment of distal radial fractures with antegrade intramedullary Kirschner wires. Strategies Trauma Limb Reconstr 2013 Aug;8(2):89-95.

6. Aro HT, Koivunen T. Minor axial shortening of the radius affects the outcome of Colles' fracture treatment. J Hand Surg 1991;16(3):392-8.

7. Adams BD. Effects of radial deformity on distal radioulnar joint mechanics. J Hand Surg 1993;18(3):492-8.

8. Fujii K, Henmi T, Kanematsu Y, Mishiro T, Sakai T, Terai T. Fractures of the distal end of the radius in elderly patients: a comparative study of anatomical and functional results. J Orthop Surg 2002;10(1):9-15.

9. Clancey GJ. Percutaneous Kirschner-wire fixation of Colles fractures. A prospective study of thirty cases. J Bone Joint Surg 1984 Sep;66(7):1008-14.

10. Kurup HV, Mandalia V, Shaju A, Beaumont A. Bicortical Kwires for distal radius fracture fixation: How many? Acta orthopaedica Belgica. 2007 Feb;73(1):26.

11. Crenshaw J. Fractures of the shoulder girdle, arm, and forearm. Campbell's operative orthopaedics. 1992:989-1053. 
12. Kapandji A. Intra-focal pinning of fractures of the distal end of the radius 10 years later. Annales de chirurgie de la main: organe officiel des societes de chirurgie de la main. 1987;6(1):57.

13. Miyake T, Hashizume H, Inoue H, Shi Q, Nagayama N. Malunited Colles' fracture Analysis of stress distribution. J Hand Surg 1994 Dec ;19(6):737-42.

14. Singh S, Trikha P, Twyman R. Superficial radial nerve damage due to Kirschner wiring of the radius. Injury 2005 Feb;36(2):3302 .

15. Van Aaken J, Beaulieu JY, Della Santa D, Kibbel O, Fusetti C. High rate of complications associated with extra focal kirschner wire pinning for distal radius fractures. Chirurgie de la Main. 2008;27(4):160-6.

16. Chia B, Catalano III LW, Glickel SZ, Barron OA, Meier K. Percutaneous pinning of distal radius fractures: an anatomic study demonstrating the proximity of K-wires to structures at risk. J Hand Surg 2009 Jul;34(6):1014-20.

17. Hargreaves DG, Drew SJ, Eckersley R. Kirschner wire pin tract infection rates: a randomized controlled trial between percutaneous and buried wires. J Hand Surg 2004 Aug;29(4):374-6.
18. Hutchinson DT, Strenz GO, Cautilli RA. Pins and plaster vs external fixation in the treatment of unstable distal radial fractures: a randomized prospective study. J Hand Surg 1995;20(3):36572.

19. Lenoble E, Dumontier C, Goutallier D, Apoil A. Fracture of the distal radius. A prospective comparison between trans-styloid and Kapandji fixations. J Bone Joint Surg 1995 Jul;77(4):562-7.

20. McBirnie J, Court-Brown CM, McQueen MM. Early open reduction and bone grafting for unstable fractures of the distal radius. J Bone Joint Surg 1995 Jul;77(4):571-5.

21. Higgins TF, Klatt J, Bachus KN. Biomechanical analysis of bicondylar tibial plateau fixation: how does lateral locking plate fixation compare to dual plate fixation? J Orthop Trauma 2007;21(5):301-6.

22. Gaikwad KB, Joshi NG, Selkar SP. Study of nitrosative stress in Pregnancy Induced Hypertension. J Clin Diagn Res 2017;11(3): BC06.

23. Cladius S, Jadhav U, Ghewade B, Ali S, Dhamgaye T. Study of diabetes mellitus in association with tuberculosis. J Datta Meghe Inst Med Sci Uni 2017;12(2):143. 